\title{
Culture and 'Khichri' identities in Diaspora: A Study in selected short stories
}

\author{
B.Sreekanth Reddy \\ Lecturer in English, Rajiv Gandhi University of Knowledge Technologies, R.K.Valley, Kadapa dist, Andhra \\ Pradesh
}

\begin{abstract}
In the post colonial phase of literary practices, the issues pertaining to the existence of immigrants and expatriates have become a fascinating subject for the writers of Indian Diaspora. While presenting the cross-cultural sensibility, the writers mainly restrict themselves to the social life of the expatriates and their desperate struggle to seek an identity in an alien cultural climate, An attempt is made in this paper to analyse the trauma and evaluate the transcultural influences in the era of globalization.Shift of geography is the determining force in the process of hybridity and multiculturalism which rocks the integration of the self and this becomes the pivotal issue of the crises. This article is used to present the issue of culture that is becoming increasingly relevant in the modern world. It attempts to show how the immigrants maintain and sustain their cultural identities. Cultural identity is formed through an interaction of tradition, history, spiritual and societal values. These issues are rightly exposed through the two short stories of Bharathi Mukherjee's Lady from Lucknow and Anuradha M. Mitra's "Romantic Stereotypes"
\end{abstract}

The study of the history of Indian migrating to other parts of the world has been an the subject of study for a considerable period of time. The cultural identity has two significant aspects for the Indians. One of them is religious element and the other one is related with their daily routine work.

The famous scholar Stuart Hall in "Cultural Identity and Representation" remarks that "we all write and speak from a particular place and time, from a history and a culture which is specific. What we say is always 'in context' positioned" (222). Hall's statement is a reminder that immigrants experience and their lives are shaped by the social location. Their history, their culture, their geographical location, as well as other elements go into the formation of their cultural identities. The present article is a study on the issues that are gaining relevance in the modern world - namely caste, religion and culture. An attempt is made to present how the immigrants maintain, sustain and develop their cultural identities. (telugu sireesha)

T.S.Eliot, in his analysis of culture, categorically admits that culture is deep and infinite, pure and imperishable as religion. He states that religion and culture besides meaning different things from each other, should mean for the individual and for the group something towards which they strive, not merely something they possess, (Eliot:Notes:31). It implies that culture is a comprehensive term that includes all those independent as well as interdependent elements that contributes to a composite ideology which determines the ways of human existence. It also implies that human identity is closely associated with the cultural identity of specific society, age, country, tradition, nationality, caste, religious practices and geographical surrounding.

The migrants suffer a serious trauma in their newly accepted identity as immigrants in the alien nation. For them it is not only a challenge of geographical displacement but also a challenge for transformation of cultural ideologies as well the diasporic writers investigate the bi-cultural pulls which create a type of double consciousness and present these aspects through their characters in the novels and short stories. These characters caught in the struggle between two cultures make continuous efforts to maintain a balance and reconstruct their identity.

But in spite of their efforts for assimilation and acculturation, they still posses a speck of fractured identity because they can't forgo their autonomy of 'self' and national cultural identity. Homi Bhabha, in his most popular essay The Location of Culture postulates how cultural alienation generates the psyche of 'marginality' and the felling of 'not belonging' which reduces them to a state of 'non-recognizable entity'. He states that Cultural differences must be understood as the free play of polarities and pluralities in the homogenous empty time of the nation community ......The analytical of cultural differences intervenes to transform the scenario of articulation...... The aim of cultural differences is to rearticulate the sum of knowledge from the perspectives of the signifying position of the minority that resists totalisation....producing other spaces of subaltern signification. (Bhabha: 162).

Culture on the whole makes two kinds of impact on it adherents. On the one hand, it promotes certain activities and experiences with some values, but on the other it imposes certain constraints. These constraints can be direct or indirect. Many societies around the world have obtained multicultural perspectives during the 
recent decade. The reason for this is the migration of the people from one country to another. Most often it is evident that people from developing countries migrate to developed countries. There they tend to assimilate the new culture and try to establish their own cultural identity. Cultural identity is formed through an interaction of tradition, history, spiritual and societal values. Tradition is a link between the past and the present and involves an active interaction of approval and disapproval of beliefs and customs.

This article deals with the reflection of culture in the various diasporic writings and the ways in which the writers deal with the concept in terms of both Indian and regional identities. Indian immigrants in the western countries particularly in the United States form a new identity while maintaining the notion of traditional culture. Indians are a diverse group of different cultures but are held together by the dreams of national identity and rich cultural heritage. There are certain problems and cultural conflicts that Indians face during the process of acculturation. These issues are a result of Western value system, which are very different from that of their homeland. The situation demands continuous adjustments, resulting in stress, frustration and hopelessness. Most Indian families try to maintain their traditional pattern but due to strong oppressive forces, they learn to adjust.

These adjustments can be noticed in the writings of the diasporic writers. So an attempt is made to bring to light some of the short stories in which the characters confront with cultural issues and how they react to overcome those challenges. Most of Bharathi Mukherjee's writings deal with the projection of cultural confrontation between the East and West. This concept is clearly portrayed in the collection of short stories in Darkness. In these short stories the immigrants are found struggling with the cultural codes of the New and Old communities.

The story "Lady from Lucknow" presents the changing status of a woman when she is culturally transplanted. Nafeesa is a Muslim woman from Lucknow who marries Iqbal and immigrates to a foreign land. Though hers was an arranged marriage at the age of seventeen, she had always yearned for passionate pleasures defying all established taboos. It indirectly contrasts the puritanical upbringing of Islamic women with her own craving for sexual and romantic desires. She develops an extra marital affair with Dr.James Beamish, a Pakistani and later she realizes her mistake at the end.

The story begins with an incident in Nafeesa's neighbourhood in Lucknow back in India. Husseina who stays next door to Nafeesa falls in love with a Hindu. They stay in a Muslim locality, which is very sensitive to the conventional affairs. Later Husseina's father gets to know of his daughters love, he beats her to death.

Her father intercepted a love note from the boy, and beat her with his leather sandals. She died soon after ...... and I pictured the dead girl's heart - rubbery squeezable organ with ...... a fruit swelling, then bursting and coating the floor with thick, slippery blood. (Mukherjee, "A Lady from Lucknow" 23).

Through this incident we notice the cultural conflicts in the same country, but between people of different religious identities.

There are certain problems and concerns that Indians might face during the process of acculturation. These issues crop up due to the Western value system, which is significantly different from that of their homeland. Indian immigrants experience strong reaction while shifting to an unfamiliar foreign culture and on missing their families and extended families. These actions demands continuous adjustments, resulting in stress, frustration and hopelessness. Most Indian families try to maintain their traditional pattern, but due to forces in American society they encounter severe stress and frustration.

The cultural difference is brought back when Nafeesa has an extra - marital affair with James. When Kates Beamish, James wife, discovers Nafeesa and James in bed, she doesn't react to it furiously. Her silence tortures Nafeesa. Suddenly Nafeesa sees herself caught in a different patriarchal paradigm, that of the white man's colored mistress in a new version of the colonial era. Her realization of her own exploitation as a sexual object is ironic because she has only exchanged the polygamous code of Islamic tradition for white male patriarchy in America.

This gives us the picture of an Indian woman who is exposed to a new culture. Her guilt pricks her mind and points at her culture. The immigrants say that the American society had an impact on their views on marital relationships. They find themselves halfway between the traditional Indian views and the 'progressive' American values. They sometimes try to move towards the opposite end, trying to assimilate the western ways of living.

By the aid of this short story, the conflict in the social and cultural codes of the East and the West, the Old and the New shows the hopeless binary nature of all human desires. Here the protagonist tries to break the taboos of her traditional culture and finally end up in a messy situation.

Anuradha M. Mitra's "Romantic Stereotypes" in Contours of the Heart is the story of a husband and wife using a new process to maintain their traditions and culture. This is a story in the form of letters, Rahul, an immigrant in the United States writes back to his wife who is about to migrate to America. Sunila is depicted as one waiting to be accepted into American life; whereas Rahul is seen as the one has adjusted to American life. 
He writes about the difficulties of being a non white in the white American society. He says that he is unrelated to the fast-paced world.

The use of images like 'Khichri' is used in terms of emotions of the immigrants. This exemplifies that being an immigrant is like being a mixture of all customs, adapting to the new ones and remaining tied to the past. In the same way, Rahul adjusts according to the changes in society, adopting the western culture and at the same time maintaining his own. He says:

I am like 'Khichri' incarnate, being indeterminately molded into whatever pot will contain my shape. My individuality lies awash in the saffron flavored soft, textures ........ My national, racial and ethnic identities work overtime to conceal rather reveal. (Mitra, "Romantic Stereotypes"424).

The other image is that of wine. He guides his wife in the letter about her behavior during the flight. He suggests her to accept the wine served during the flight and give less heed to people watching her having the wine. It explains that Rahul guides her to accept the new culture and traditions of the alien land though they seem different. He asks her to pay less attention to her cultural past for it will only confuse them in the world of new cultures. In other words, he is suggesting that one should adjust and try to adopt the new culture though it is difficult, and not grumble about it and spoil the new taste it provides. Rahul is shown as a person who adjusts to the alien land and its culture. Sunila is exposed differently through her letters to her aunt. Her dissatisfaction of the land of opportunities is well depicted all through the letters. She frequently questions her aunt about the varied identities in America. She is disappointed and faces identity crises:

Is it because our sense of self is established in opposition to rather than in partnership with the rest of white or black or yellow American? Is it this that makes us crumble and grow weak inside so that we become strangely inarticulate in expressing who we are? (ibid,427).

While Rahul strives for his position, Sunila opposes the negation of herself. Generally, men are not deeply bound by traditions and Customs, whereas women are deeply bound. They stick to certain sentiments about their culture. Thus the author successfully portrays the differences in men and women adapting to Western culture.

The image of 'Khichri' signifies a mixture of cultures. The ingredients mixed to give taste to the 'Khichri' are the people from different regions who come together to stay united and take the best of both lands. Thus the diasporic writers' analyses that the immigrants would like to preserve their caste, religion and culture. They view these as integral parts of their ethnic and cultural identities. Cultural identity is a powerful issue for Indians and it is well reflected in the short stories and novels of diasporic Indian writers. The characters show a strong sense of ethnic identification with their root cultures.

\section{Works Cited}

- $\quad$ Bhabha, Homi. The Location of Culture. London: Routledge, 1994.

- Eliot, T.S.Notes Towards The Definition of Culture. London: Faber, 1948.

- Jasbir Jain. "Introduction” Writers of Indian Diaspora (ed), Rawat Publications, New Delhi, 2003

- Mukherjee, Bharathi. Darkness. Penguin: New Delhi: 1990

- Mitra, Anuradha M. "Romantic Stereotypes” Maira and Srikanth (421-429)

- Sireesha Telugu, Diasporic Indian Women Writers. Prestige Publications New Delhi: 2009

- Rutherford J., ed. Identity: Commuity, Culture, Difference. London: Lawrence, 1990

\section{Bio Note}

Name : B Sreekanth Reddy

Qualifications : M.A., M.Ed., M.Phil.,(PhD)

Experience : Eight years of experience in teaching English at various levels.Presently working for an Engineering college. Areas of interest are teaching soft skills, ELT, Diaspora and Subaltern studies. Presented and published a number of articles on different themes of ELT and English Literature.in various National and International journals

\section{Declaration}

I B.Sreekanth Reddy, submit that the article Culture and 'Khichri' identities in Diaspora: A Study in selected short stories is an original work of mine and any text taken from other sources are properly acknowledged. I personally take the resonsibility of any discripancy regarding the originality of the text 